\title{
Lithium-ion battery separator membranes based on poly(L-lactic acid) biopolymer
}

J. C. Barbosa ${ }^{1,2}$, Ander Reizabal ${ }^{3,4}$, D.M. Correia ${ }^{1,2}$, A. Fidalgo-Marijuan ${ }^{3,5}$, R.

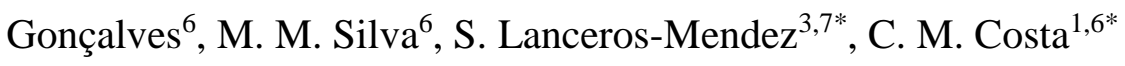

${ }^{1}$ Center of Physics, University of Minho, 4710-058 Braga, Portugal

${ }^{2}$ Department of Chemistry and CQ-VR, University of Trás -os -Montes e Alto Douro, 5000-801 Vila Real, Portugal

${ }^{3}$ BCMaterials, Basque Center for Materials, Applications and Nanostructures, UPV/EHU Science Park, 48940 Leioa, Spain.

${ }^{4}$ Macromolecular Chemistry Research Group (LABQUIMAC). Dept. of Physical Chemistry. Faculty of Science and Technology. University of the Basque Country (UPV/EHU), Spain.

${ }^{5}$ Mineralogía y Petrología, Universidad del País Vasco (UPV/EHU), Barrio Sarriena s/n, Leioa, Bizkaia 48940, Spain

${ }^{6}$ Center of Chemistry, University of Minho, 4710-058 Braga, Portugal

${ }^{7}$ Ikerbasque, Basque Foundation for Science, 48013 Bilbao, Spain

\section{*Corresponding Authors}

Email: S. Lanceros-Méndez (senentxu.lanceros@bcmaterials.net); C. M. Costa (cmscosta@ fisica.uminho.pt) 


\begin{abstract}
:
Sustainable materials are increasingly needed in lithium ion batteries in order to reduce their environmental impact and improve their recyclability. This work reports on the production of separators using poly (L-lactic acid) (PLLA) for lithium ion battery applications. PLLA separators were obtained by solvent casting technique, by varying polymer concentration in solution between $8 \mathrm{wt} . \%$ and $12 \mathrm{wt} . \%$ in order to evaluate their morphology, thermal, electrical and electrochemical properties. It is verified that morphology and porosity can be tuned by varying polymer concentration and that the separators are thermally stable up to $250{ }^{\circ} \mathrm{C}$. The best ionic conductivity of $1.6 \mathrm{mS} / \mathrm{cm}$ was obtained for the PLLA separator prepared from $10 \mathrm{wt} . \%$ polymer concentration in solution, due to the synergistic effect of the morphology and electrolyte uptake. For this membrane, a high discharge capacity value of $93 \mathrm{mAh} \cdot \mathrm{g}^{-1}$ was obtained at the rate of $1 \mathrm{C}$. In this work, it is demonstrated that PLLA is a good candidate for the development of separator membranes, in order to produce greener and environmentally friendly batteries in a circular economy context.
\end{abstract}

Kewyords: PLLA; separator; degradable; lithium-ion batteries 


\section{Introduction}

Energy storage systems are necessary to supply energy and power in portable electronic devices and electrical vehicles, among others. In particular, considering the advances in electronic miniaturization, there is a demand for smaller and lighter batteries with enhanced performance [1]. Lithium-ion batteries are energy storage systems that meet the above specifications, with a global battery market of $75 \%$ which is expected to grow by around 7\% annually until 2024 [2]. Lithium-ion batteries present specific advantages when compared to other battery types, such as high energy density, low self-discharge, no memory effect and higher number of charge/discharge cycles $[3,4]$.

To improve battery performance in lithium-ion batteries, key issues such as specific energy, power, safety and reliability must be addressed. These issues depend on the characteristics of the materials for the different battery components [5]. A lithium-ion battery consists of a negative electrode (anode) and a positive electrode (cathode), which are separated by a porous membrane called a separator $[6,7]$. The separator is essential to improve battery performance. It can be based on different types of porous materials, including microporous membranes, nonwoven membranes, electrospun membranes, membranes with external surface modification, composites or polymer blend membranes [8]. The main functions of the separator are to promote a medium for ions to transfer between the electrodes, prevent physical contact between the anode and the cathode, regulate cell kinetics and improve safety in the charge and discharge mechanism, as well as to warrant battery mechanical stability $[4,9]$. Separator properties mainly depend on its physical-chemical characteristics including thickness, permeability, overall porosity, pore size and interconnectivity, wettability, electrolyte absorption and retention, and chemical, thermal and mechanical stability [10]. Regardless of the separator type, they are mostly based on porous membranes [8]. The incorporation of the lithium solution is 
usually achieved by uptake, through the immersion of the polymer membrane directly within the lithium-ion solution until the weight remains unchanged [11].

Different processing techniques can be used to obtain porous materials, such as thermal induced phase separation, template synthesis, self-assembly or even electrospinning [12]. Different polymer materials including poly(ethylene), PE [13], poly(propylene), PP [14], poly(methyl methacrylate), PMMA [15], poly (ether-ether-ketone) (PEEK) [16], poly(acrylonitrile), PAN [17], polyimide (PI) [18], Nylon 6.6 [19], poly(vinylidene fluoride), PVDF [20], poly(vinylidene fluoride-co-hexafluoropropene), PVDF-HFP [21] and poly(vinylidene fluoride-co-trifluoroethylene, PVDF-TrFE [20] are being explored for battery separator applications [7].

Commercial separators basically rely on polyolefin polymers based on their mechanical stability and chemical stability, good electrochemical performance and low cost [22]. The drawbacks of these separators are their hydrophobic behavior, high flammability and, considering environmental issues, their difficult recyclability, not being in agreement with the circular economy and sustainability paradigms [10]. Considering those issues, new types of separators based on natural polymers, including cellulose derivatives, eggshell membranes or poly(vinyl alcohol), have been proposed due to the low production cost, good physical and chemical properties and suitable performance as separators [23-25]. In this context, it is interesting to explore the suitability of poly-1lactic acid (PLLA) for battery separator applications. PLLA is a biocompatible and biodegradable enantiomeric polyester produced from lactic acid synthesis [26]. Further, PLLA presents a broad spectra of processing morphologies, including films [27, 28], electrospun fibers $[29,30]$ and membranes [31], as well as electroactive characteristics, with a piezoelectric constant of about $6-10$ pC. $\mathrm{N}^{-1}$ [32], enabling the possibility to integrate smart and responsive materials in battery applications [33]. The suitable 
characteristics of PLLA have been demonstrated in its applications in the field of tissue and biomedical engineering [34], agriculture [35], aquaculture [36], sensors [37] and electronics [37].

It is important to note that the interest in PLLA as a recyclable polymer has grown due to environmental concerns with conventional plastics [38]. The biodegradability of PLLA makes easier its recyclability, when compared with the most widely used polymers [39]. The life cycle assessment with respect to recycling of PLLA has proven the economic and environmental benefits of reusing the polymer instead of disposing or incinerating it [40].

PLLA has been recently investigated as gel polymer electrolytes (GPE) through the production of cellulose acetate (CA)/poly-L-lactic acid (PLLA)/Halloysite nanotube composite nanofibers. These CA/PLLA/HNT composite nanofiber membranes have been used as green skeleton materials in GPEs for lithium-ion batteries in search for high performance and environmental sustainability [41]. Also, PLLA was successfully used as a coating in a GPE, in order to suppress the growth of lithium dendrites in the battery, allowing high electrolyte uptake and retention, thermal stability, electrochemical stability and $\mathrm{Li}^{+}$transference number [42]. Nevertheless, to our knowledge, there are still no applications of this polymer directly as separator membranes for lithium ion batteries or in the electrochemistry field. In the present work, porous membranes based on PLLA were developed by thermal induced phase separation by varying polymer concentration in solution. The effect of processing conditions on the physical-chemical properties of the membranes and on the performance of the fabricated batteries was investigated. 


\section{Experimental details}

\subsection{Materials}

Poly(L-lactic acid) (PLLA) with an average molecular weight of 217.000-225.000 $\mathrm{g} \mathrm{mol}^{-}$

1 (Purasorb PL18) was supplied by Purasorb. N, N-dimethylformamide (DMF), dichloromethane (MC), N-methylpyrrolidinone (NMP) and $1 \mathrm{M} \mathrm{LiPF}_{6}$ in a mixture of ethyl carbonate (EC) and dimethyl carbonate (DMC) (1:1 in vol. ratio) were obtained from Merck. The materials were used as provided. Lithium iron phosphate, $\mathrm{C}-\mathrm{LiFePO}_{4}$ (LFP), carbon black, and poly(vinylidene fluoride), PVDF (Solef 5130) were supplied by Phostech Lithium, Super P, Timcal Graphite \& Carbon and Solvay, respectively.

\subsection{Poly(L-lactic acid) membranes processing}

PLLA membranes were obtained by the dissolution of 8,10 and $12 \mathrm{wt} \%$ PLLA polymer concentrations in dichloromethane (DMC)/dimethylformamide (DMF), in a 70:30 vol ratio, under magnetic stirring at room temperature. The choice of these solvents is due to the fact that they have different boiling points $\left(39.6^{\circ} \mathrm{C}\right.$ and $152{ }^{\circ} \mathrm{C}$, respectively). In the production of membranes using two solvents, one of them must present a high boiling point to increase the porosity of the structure. The used proportion of solvents has been previously optimized for electrospun PLLA membranes, where a viscosity below 1 Pa.s is needed [30]. After complete polymer dissolution, the solutions were placed in a Petri dish and let dry at room temperature.

The produced membranes were identified as PLLA $x$, where $x$ represents the polymer concentration. 


\subsection{Membrane morphological and physical-chemical characterization}

The morphology of the PLLA membranes was analyzed by scanning electron microscopy (SEM, Quanta 650, from FEI) with an accelerating voltage of $15 \mathrm{kV}$. The samples were previously coated with a thin gold layer using a sputter coating.

Infrared measurements (FTIR) were performed at room temperature in a Jasco FT/IR4100 system apparatus in ATR mode from 4000 to $600 \mathrm{~cm}^{-1}$, collected with 64 scans and a resolution of $4 \mathrm{~cm}^{-1}$.

Thermogravimetric (TGA) analysis was carried out in a Perkin-Elmer Pyris-1 TGA apparatus between $25^{\circ} \mathrm{C}$ and $400{ }^{\circ} \mathrm{C}$, at $10^{\circ} \mathrm{C} /$ min under a nitrogen atmosphere.

Porosity and surface area were determined by mercury intrusion porosimetry (MIP) in a Quantachrome Instruments Poremaster-60 GT operating in the pressure range from $10^{-4}$ $\mathrm{MPa}$ to $414 \mathrm{MPa}$. Samples were degassed in situ at $110{ }^{\circ} \mathrm{C}$ during $12 \mathrm{~h}$ prior to measurement. A contact angle of $140^{\circ}$, a surface tension of $480 \mathrm{dyn} \cdot \mathrm{cm}^{-1}$ for mercury and a pressure equilibration time of $11 \mathrm{~s}$ were used. Before the MIP measurements, the He density for all samples was measured in a Quantachrome Instruments automatic Micro Ultrapycnometer.

\subsection{Contact angle, uptake behavior and ionic conductivity}

The contact angle of the PLLA membranes was measured using a Data-Physics Contact Angle System and the OCA20 software, by separately depositing $3 \mu \mathrm{L}$ of ultrapure water or electrolyte drop on the surface of the membranes.

The membranes were immersed in the liquid electrolyte, consisting in a $1 \mathrm{M}$ solution of $1 \mathrm{M} \mathrm{LiPF} 6$ in EC:DMC, for 20 minutes. The uptake of the electrolyte solution $(\varepsilon)$ was evaluated by equation 1 : 


$$
\varepsilon=\left(\frac{M-M_{0}}{M_{0}}\right) \times 100
$$

where $M_{0}$ is the membrane weight and $M$ is the mass of the membrane after immersion in the electrolyte solution.

The ionic conductivity of the membranes soaked in electrolyte was determined using a constant volume support with the PLLA membranes placed between two gold blocking electrodes located inside a Buchi TO 50 oven. Impedance measurements were performed at frequencies between $500 \mathrm{mHz}$ and $65 \mathrm{kHz}$ using an Autolab PGSTAT-12 (Eco Chemie) at room temperature. The ionic conductivity $(\sigma)$ of the PLLA membranes was calculated by:

$$
\sigma=\frac{t}{A * R_{b}}
$$

where $t$ is the thickness, $A$ is the area and $R_{b}$ is sample bulk resistivity, obtained from the Nyquist plots through the interception of the imaginary impedance ( $Z$ '') and the real impedance (Z').

\subsection{Electrodes and cathodic half-cells fabrication}

The cathode electrode slurry was prepared with LFP, carbon black and PVDF as active material, conductive agent and polymer binder, respectively, in a weight ratio (\%) of 80:10:10. The PVDF binder was dissolved in NMP (40 mg/mL) to form the binder solution and the active material and conductive additive were then mixed separately in the dried state. Then, small amounts of solid material (active material and conductive additive) were added to the PVDF binder solution under constant mechanical stirring. After adding all the solid material, it was kept 3 hours under magnetic stirring (Ika, model 
no. C-MAG HS 7) at $1000 \mathrm{rpm}$ in order to achieve a good dispersion. The slurry was then spread onto the aluminium foil using a blade coater with a slit width of $200 \mu \mathrm{m}$. The electrode slurry was dried in air atmosphere at $80{ }^{\circ} \mathrm{C}$ by a conventional oven (ED 23 Binder) in order to obtain the cathodes to be used for cathodic half-cells fabrication. For these cathodes, the active mass loading and thickness were $\sim 2 \mathrm{mg} \cdot \mathrm{cm}^{-2}$ and $17 \mu \mathrm{m}$, respectively.

Swagelok cells were assembled in an argon-filled glove box with Li metal as anode, the different PLLA membranes as separators and $1 \mathrm{M} \mathrm{LiPF}_{6}$ in a mixture of ethyl carbonate (EC) and dimethyl carbonate (DMC) (1:1 in vol. ratio) as electrolyte, and the previously prepared cathode electrode.

Galvanostatic charge/discharge measurements were carried out from 2.5 to $4.2 \mathrm{~V}$ with a Biologic VMP at $\mathrm{C} / 20, \mathrm{C} / 10, \mathrm{C} / 5$ and $\mathrm{C}$-rates $\left(\mathrm{C}=170 \mathrm{~mA} \mathrm{~g}^{-1}\right)$. Impedance values before and after cycling were recorded in a frequency range from $1 \mathrm{MHz}$ to $10 \mathrm{mHz}$ with an amplitude of $10 \mathrm{mV}$ in an Autolab PGSTAT-12 (Eco Chemie) equipment. 


\section{Results and discussion}

\subsection{Morphology, polymer phase and thermal stability}

Surface SEM images in two magnifications of the different PLLA separators are shown in Figure 1. Regardless of the polymer concentration in the original solution, all membranes are characterized by a porous morphology with interconnected pores homogenously distributed along the membrane. The obtained morphology is explained by the polymer- solvent interaction and evaporation temperature, which results in both liquid-liquid (Solvent (S)- Solvent (S)) and solid-liquid (Polymer (P)-S) demixing during the phase inversion [43].
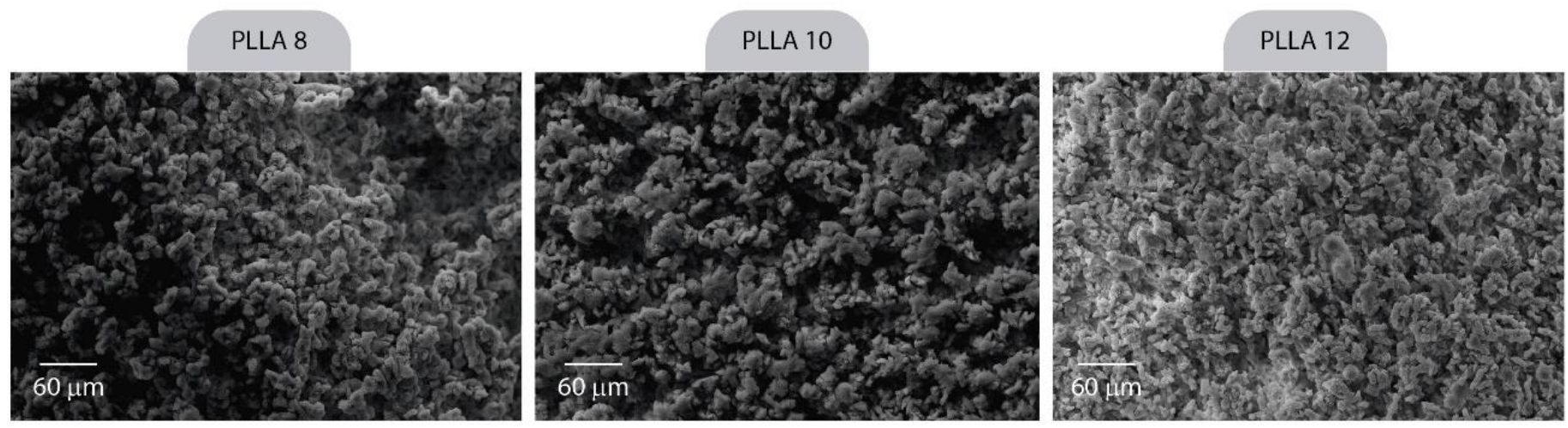

Figure 1 - Surface SEM images of the different PLLA membranes.

Figure 1 shows that the polymer concentration in the solution affects the morphology of the membranes. Increasing polymer concentration leads to a more dense and compact structure with a smaller amount of macro-voids, resulting from the increase in the viscosity of the solution [44]. The higher viscosity of the solution with a polymer concentration of $12 \mathrm{wt} \%$ suppresses the exchange rate between solvents, resulting in a denser membrane structure when compared to the other polymer concentrations [45]. This higher viscosity leads to lower diffusion of solvents within the solution, delaying the phase separation [46]. Further, the polymer concentration in the solution affects the 
thermodynamic behavior and results in early demixing, which leads to a PLLA membrane with a homogeneous structure along the sample [47].

The effect of polymer concentration on the molecular characteristics of PLLA membranes was evaluated by FTIR (Figure 2), showing that the initial polymer concentration in solution does not affect the typical infrared absorption bands of the PLLA polymer. Thus, independently of the processing solution, the absorption bands are observed at 1083 , 1175,1456 and $1754 \mathrm{~cm}^{-1}$ which correspond to $v_{\mathrm{s}}(\mathrm{C}-\mathrm{O}-\mathrm{C}), v_{\mathrm{as}}(\mathrm{C}-\mathrm{O}-\mathrm{C})+\mathrm{r}_{\mathrm{as}}\left(\mathrm{CH}_{3}\right)$, $\delta_{\text {as }}\left(\mathrm{CH}_{3}\right)$ and $v(\mathrm{C}=\mathrm{O})$, respectively [30]. Basically, these absorption bands are characteristic of the amorphous phase of the PLLA polymer [30]. In order to evaluate the interaction of the electrolyte with PLLA membranes, FTIR spectra were also recorded after the electrolyte uptake process, as shown in Figure $2 b$ ).
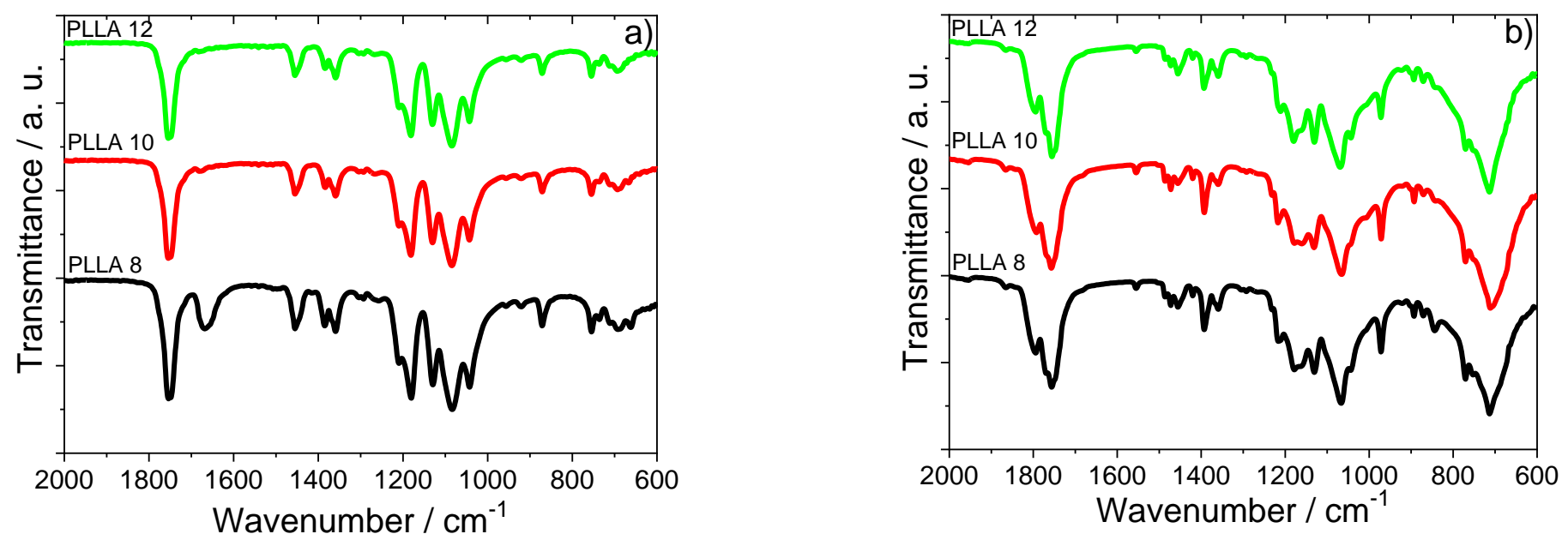


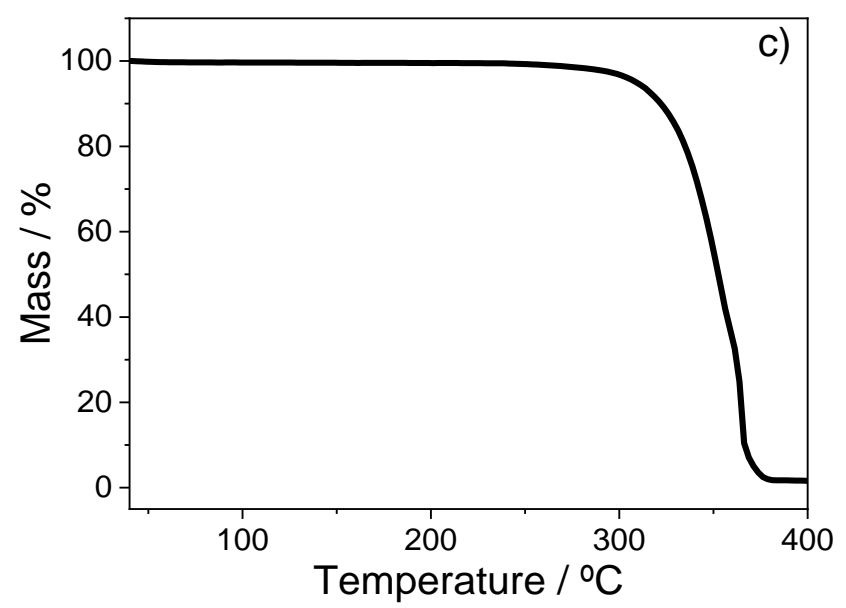

Figure 2 - FTIR spectra of PLLA membranes a) before and b) after electrolyte uptake, c) TGA curves for the PLLA 8 membrane at $10^{\circ} \mathrm{C} / \mathrm{min}$ and d) photographic images of PLLA 8 membrane before and after thermal treatment at $150^{\circ} \mathrm{C}$ for $1 \mathrm{~h}$.

Independently of the PLLA membrane, new absorption bands related to the electrolyte solution were observed at 844,970 and $1390 \mathrm{~cm}^{-1}$, corresponding to $v_{3}(\mathrm{~T} 1 \mathrm{u})$ of the "free" $\mathrm{PF}_{6}{ }^{-}$ion, $\mathrm{C} 2-\mathrm{O} 2$ and $\mathrm{C} 5-\mathrm{C} 6$ stretch and $\mathrm{H}_{2} \mathrm{C}$ scissor, as detected in Figure 2b) [48]. In addition, the interaction between the electrolyte solution and the PLLA polymer is also demonstrated in Figure $2 b$ ), based on the modification of the intensity of the absorption bands characteristics of the amorphous PLLA.

The thermal degradation of the PLLA membranes is presented in Figure 2c). Only the degradation profile of the PLLA 8 membrane is shown, being representative for the behavior of all membranes. Figure 2c) shows that the degradation profile is very stable up to $250^{\circ} \mathrm{C}$ due to the hydrophobic nature of the polymer. The PLLA degradation occurs then in a single step above $300{ }^{\circ} \mathrm{C}$, with the formation of aldehyde groups [49]. The degradation products of the PLLA polymer include lactide and/or cyclic oligomer by interchange and by chain homolysis [49]. Considering the safety of the battery, thermal stability is an important factor that must be taken into account. Figure 2d) shows the photographic images of the PLLA 8 membrane (as representative of all membranes) 
before and after thermal treatment at $150{ }^{\circ} \mathrm{C}$ for 1 hour. Further, Figure 8 also shows that the PLLA membrane presents no shrinkage at $150{ }^{\circ} \mathrm{C}$, being suitable for lithium-ion battery applications, also due to the necessary mechanical flexibility (compression force, data not shown). The stress-strain curve of the PLLA membrane prepared from a polymer concentration in solution of 8 wt.\% is shown in Figure S1 of the supplementary information. Figure $\mathrm{S} 1$ shows that the membranes present a Young modulus of $7.5 \mathrm{MPa}$ and adequate mechanical properties for being used in lithium-ion batteries as a porous separator. The mechanical results are similar for the rest of the membranes.

The porosity values and surface area values of the different PLLA membranes are presented in Table 1.

Table 1 - Different Porosity values and surface area of the PLLA membranes as determined by mercury intrusion porosimetry.

\begin{tabular}{|c|c|c|c|c|}
\hline & $\begin{array}{c}\text { Total } \\
\text { Porosity } \\
(\boldsymbol{\%})\end{array}$ & $\begin{array}{c}\text { Interparticle } \\
\text { porosity }(\boldsymbol{\%})\end{array}$ & $\begin{array}{c}\text { Intraparticle } \\
\text { porosity }(\boldsymbol{\%})\end{array}$ & $\begin{array}{c}\text { Surface area / } \\
\mathbf{~}^{\mathbf{2}} \mathbf{g}^{\mathbf{- 1}}\end{array}$ \\
\hline PLLA-8 & $74.7 \pm 2.2$ & $63.5 \pm 2.2$ & $11.2 \pm 2.2$ & $40.3 \pm 1.2$ \\
\hline PLLA-10 & $72.7 \pm 2.2$ & $54.9 \pm 2.2$ & $17.8 \pm 2.2$ & $53.6 \pm 1.6$ \\
\hline PLLA-12 & $71.7 \pm 2.2$ & $56.4 \pm 2.2$ & $15.3 \pm 2.2$ & $40.6 \pm 1.2$ \\
\hline
\end{tabular}

Through the analysis of Table 1, it is observed that the overall porosity of all PLLA membranes is very close to $72 \%$. Table 1 shows that the polymer concentration affects the interparticle and intraparticle porosity values, the number and distribution of pores being different for the different PLLA membranes. The low value of the interparticle porosity of the PLLA membrane with a polymer concentration of $10 \mathrm{wt} . \%$ results from the small pore sizes between the particles, leading to pores with high interconnectivity and high surface area. The different interparticle and intraparticle porosity values of the 
samples are related to the overall pore morphology and are important to improve wettability, electrical properties and mechanical stability [50].

\subsection{Contact angle, uptake process and ionic conductivity value}

To assess the wetting behavior of the PLLA membranes, the contact angle was determined for a water solution. Further, the contact angle of the membranes was also evaluated after the deposition of a drop of the electrolyte solution. In this case, when a drop of the electrolyte solution was added to the surface of the PLLA membranes, it was absorbed immediately. Figure 3a) shows the contact angle values for the PLLA membranes. Contact angles below $100^{\circ}$ are observed, with the lowest value of $61^{\circ} \pm 6$ being obtained for the PLLA 10 membrane, which presents a hydrophilic character [51]. The behavior of the contact angle is correlated with the surface area value, and the contact angle follows the order: PLLA $8<$ PLLA $12<$ PLLA 10.
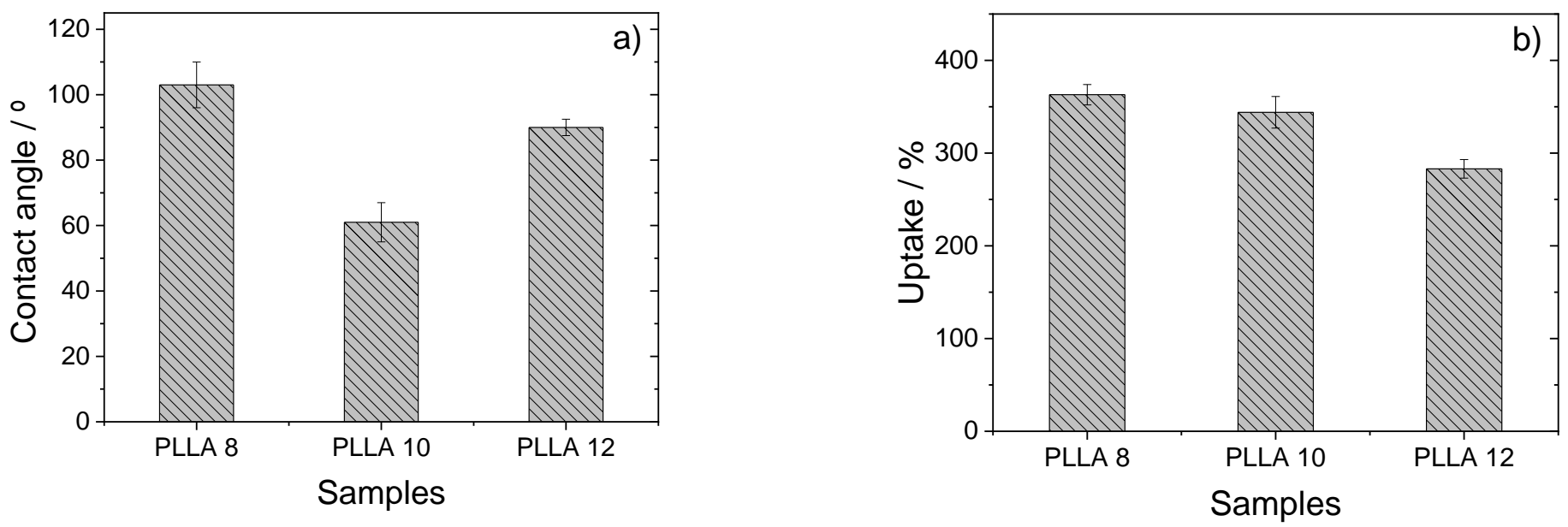

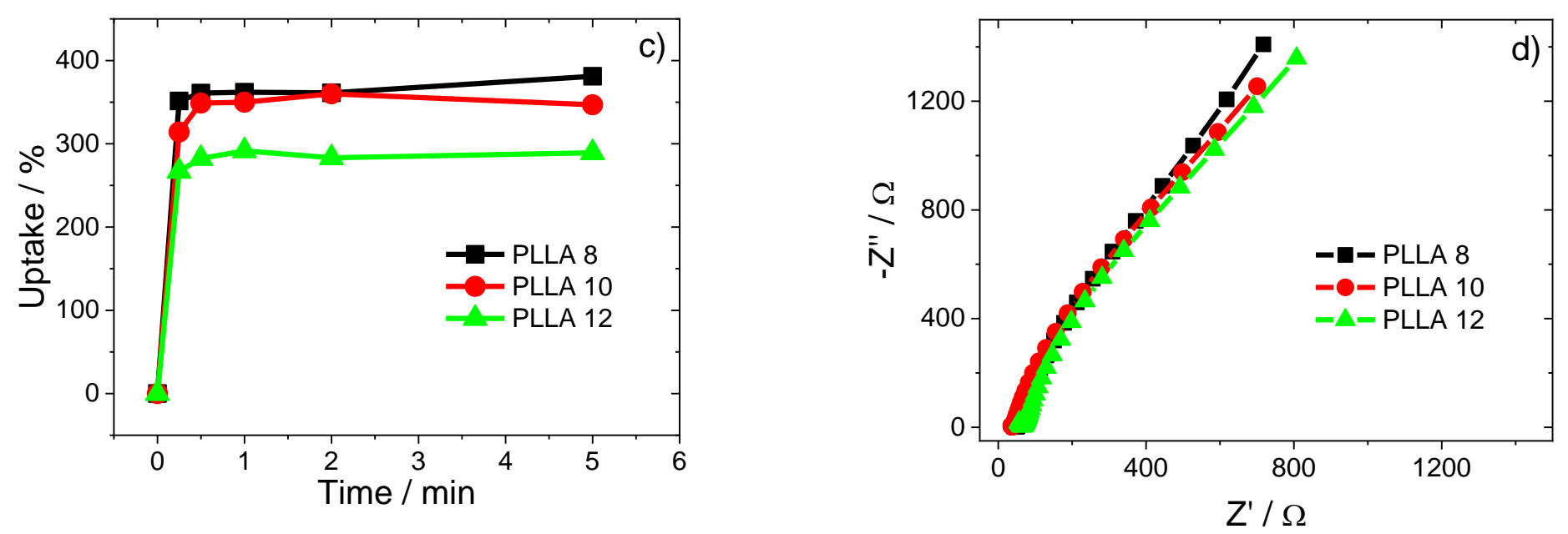

Figure 3 - Measurements of a) contact angle, b) electrolyte uptake value, c) uptake as a function of the time and d) room temperature Nyquist plots of the PLLA membranes.

The wettability of the membranes has significant influence in their electrolyte uptake capacity. A high wettability means improved affinity between the membrane and the electrolyte, which facilitates its penetration into membrane structure [52]. Also, the electrolyte uptake capacity is affected by the membrane's porosity. The increase of the porosity leads to an increase of the surface area, enhancing the electrolyte uptake capacity [53]. The uptake value was determined after placing the PLLA membrane in the electrolyte solution for 20 minutes. Figure $3 \mathrm{~b}$ ) shows the uptake value for the PLLA membranes, showing that a maximum is obtained for PLLA 8 around 350\%. For the other membranes, the uptake value is greater than $250 \%$. The uptake process is in fact very fast and the weight of the PLLA membranes does not change after 1 minute in the solution (Figure 3c)). In addition, after 15 days, the PLLA separator does not break in the electrolyte solution.

The uptake capacity is the main factor that influences the ionic conductivity of the membranes, as the addition of electrolyte increases the ionic conductivity of the separators [54]. After the uptake process, the ionic conductivity was determined by 
placing the PLLA membrane with electrolyte solution between two gold blocking electrodes, i.e, gold / PLLA membrane / gold cell. Figure 3d) shows the Nyquist plots for all PLLA membranes in which the observed straight line represents the electrode/electrolyte double layer capacitance behavior [25]. In the Nyquist plot of Figure $3 d)$, the bulk resistance $\left(R_{b}\right)$ of the PLLA separator is obtained by the high-frequency intercept on the $\mathrm{Z}^{\prime}$ axis. The obtained values are $50 \Omega, 38 \Omega$ and $66 \Omega$ for PLLA 8 , PLLA 10 and PLLA 12, respectively. The ionic conductivity value was the calculated using equation 2 and the values are presented in Table 2.

Regardless of the polymer concentration in solution, the ionic conductivity of the membranes is greater than $10^{-4} \mathrm{~S} / \mathrm{cm}$ [55], which is the minimum value for their use in lithium-ion batteries. The highest ionic conductivity value is obtained for PLLA 10 due to the combination of the uptake value and the high surface area resulting from the open pore structure.

Table 2 - Ionic conductivity $(\sigma i)$, tortuosity $(\tau)$ and MacMullin number $\left(\mathrm{N}_{\mathrm{M}}\right)$ of the PLLA membranes

\begin{tabular}{|c|c|c|c|}
\hline & $\boldsymbol{\sigma i} / \mathbf{~ m S . c m}^{-1}$ & $\boldsymbol{\tau}$ & $\mathbf{N}_{\mathbf{M}}$ \\
\hline PLLA-8 & $1.5 \pm 0.2$ & 2.4 & $8 \pm 1$ \\
\hline PLLA-10 & $1.6 \pm 0.2$ & 2.3 & $7 \pm 1$ \\
\hline PLLA-12 & $0.9 \pm 0.1$ & 3.0 & $13 \pm 2$ \\
\hline Celgard $^{\circledR} \mathbf{2 4 0 0}[\mathbf{5 6}]$ & $0.6 \pm 0.1$ & 2.3 & $16 \pm 2$ \\
\hline
\end{tabular}

Through the ionic conductivity value, the tortuosity $(\tau)$ [57] and MacMullin number $\left(\mathrm{N}_{\mathrm{M}}\right)$ [58] were calculated, respectively, through the following equations:

$$
\begin{aligned}
\tau & =\sqrt{\frac{\sigma_{0} \varepsilon}{\sigma_{i}}} \\
N_{M} & =\frac{\sigma_{0}}{\sigma_{i}}
\end{aligned}
$$


where $\sigma_{0}$ is the ionic conductivity of the electrolyte solution $\left(11.19{\mathrm{mS} . \mathrm{cm}^{-1}}^{-1}\right.$ at $\left.25^{\circ}\right), \varepsilon$ is the porosity of the PLLA membrane, and $\sigma_{\mathrm{i}}$ is the ionic conductivity of the membrane and the electrolyte solution at room temperature.

The tortuosity describes the elongation of the transport path due to the porous structure, with respect to a straight line $\mathrm{d}$, and the ideal value is 1 [57]. Table 2 shows that all PLLA membranes are characterized by a low tortuosity value. The tortuosity values of commercial separator are between 2.5 to 4.1 [57], being lower for the PLLA 8 and PLLA 10 membranes obtained in the present work. These values are similar to the typical tortuosity of a commercial separator [56].

The MacMullin number describes the resistance of the separator [58]. The PLLA membrane with the lowest MacMullin number is PLLA 10, which is related to its ionic conductivity and surface area values. This value is significantly lower than that found for commercial Celgard ${ }^{\circledR} 2400$ membranes [56].

\subsection{Battery performance}

Considering the ionic conductivity values obtained for the PLLA membranes (Table 2), galvanostatic measurements between 2.5 to $4.2 \mathrm{~V}$ were performed at room temperature. Different C-rates were used to demonstrate the viability of the PLLA membranes as a battery separator for lithium-ion batteries. Figure 4a) shows the charge/discharge profiles for PLLA 10 at C/20, C/10, C/5 and C-rates. For the rest of the PLLA membranes, these profiles are similar and are all described by two voltage plateaus for charge and discharge behavior. These plateaus represent the lithium removal and lithium insertion, respectively, through the redox reactions $\mathrm{Fe}^{2+} / \mathrm{Fe}^{3+}$ in the LFP cathode material [59]. 

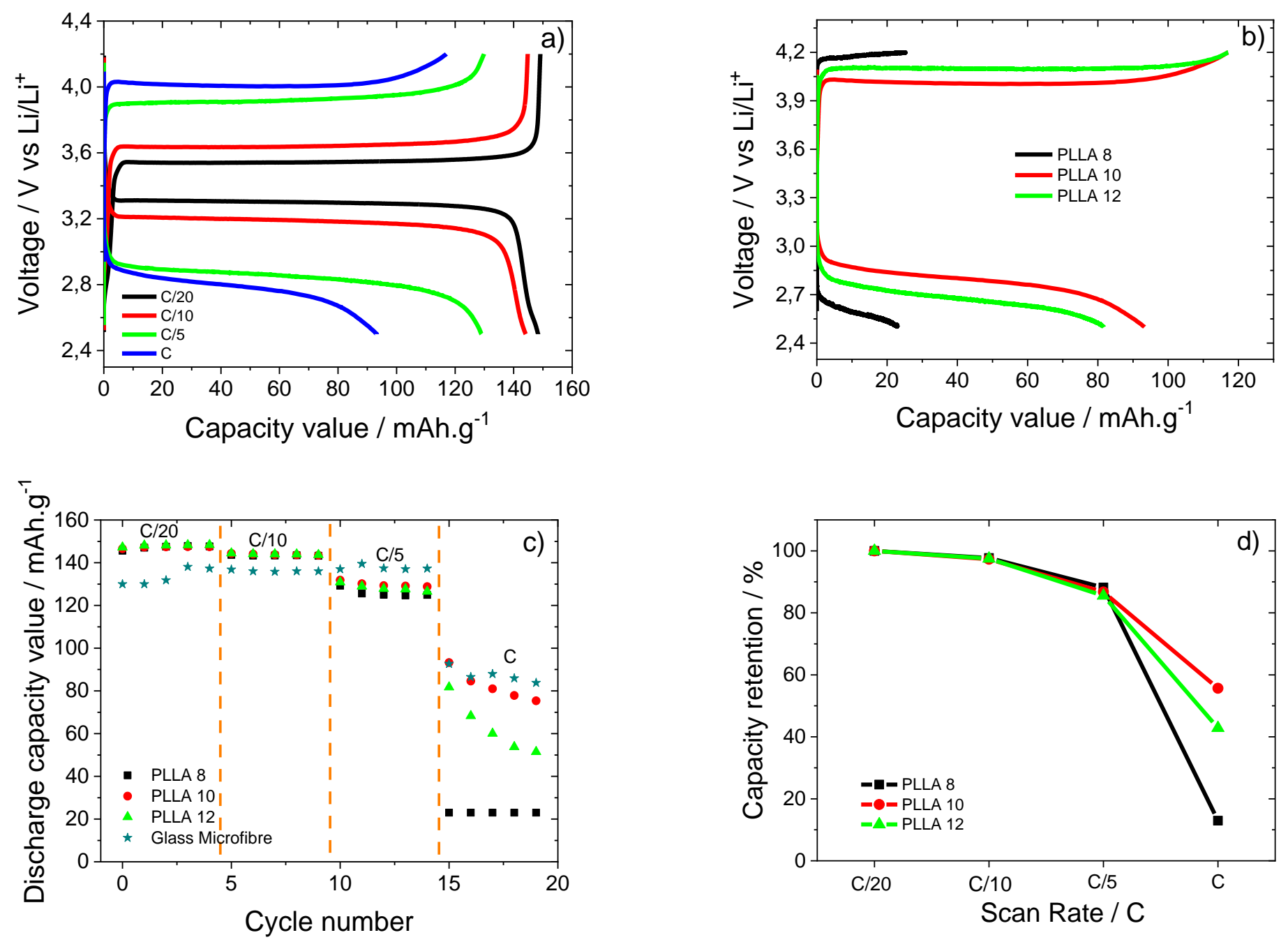

Figure 4 - a) Charge/discharge C-rate profiles for the half-cell with the PLLA 10 membrane; b) first charge/discharge curve at C-rate for half-cells with the different PLLA membranes; c) rate performance as a function of the cycle number and d) capacity retention for all the membranes in half-cell batteries.

Figure 4a) shows that the discharge capacity value decreases with increasing scan rate due to the electrochemical polarization effect, which is related to the slow charge transfer process caused by the electronic resistance in the electrodes [60, 61]. Figure $4 b$ ) shows the first charge/discharge profile at C-rate for all PLLA membranes. For this C-rate, it is observed that different discharge capacity values are obtained for the PLLA separators and that the PLLA membrane with the highest discharge capacity value is PLLA 10, 
which presents the lowest polarization (Figure 4c)). Basically, this behavior is related to the ionic conductivity value of the PLLA membranes.

The rate performance capability at the different C-rates for all PLLA membranes is shown in Figure 4c). It is observed that the discharge capacity value is very stable as a function of cycles at C-rates below C. For C-rate and regardless of the PLLA membrane, the discharge capacity value decreases according to the cycle number. This behavior is attributed to the increase of charge transfer resistance and the higher electrical resistance value that affects the insertion and reinsertion process of lithium-ions [62]. Figure 4c) shows the comparison of the battery performance of the PLLA separators with a commercial glass microfiber separator at different $\mathrm{C}$ rates. Analyzing Figure 4c), it is observed that the PLLA membranes present higher discharge values when compared to the glass microfibers at rates below C. At C-rate, only the PLLA 10 membranes show a discharge capacity similar to the commercial separator.

Figure 4d) shows the discharge capacity retention as a function of the scan rate, in which the PLLA 10 and PLLA 12 show higher discharge capacity retention, 55\% and 44\%, respectively, at C-rate. This fact is attributed to the high ionic conductivity and surface area value of PLLA 10.

In order to evaluate the cycling stability of the PLLA membranes, Figure 5a) shows the discharge capacity value of the PLLA 10 over 50 cycles. For other PLLA membranes, this behavior is similar. Analyzing Figure 5a), it is observed that the discharge capacity value is very stable as a function of cycle number and, for PLLA 10, the capacity fade is $\sim 7 \%$. In addition, the coulombic efficiency for PLLA 10 is $\sim 100 \%$, which describes the reversibility of the process, as shown in Figure 5a) [63].

To assess the electrochemical performance of half-cell batteries with PLLA separators, the electrochemical impedance spectra of the Nyquist plot for these batteries were 
performed before and after cycling, as shown in Figure 5b) and c), respectively. Regardless of the PLLA membrane, this Nyquist plot is characterized in the high and medium frequency regions by a semicircle that represent the sum of the ohmic resistance, contact film resistance and charge-transfer reaction resistance (Figure 5b)) [64]. Also, in the Nyquist plot low frequency region, a straight line is observed that is associated with the $\mathrm{Li}^{+}$diffusion process [65].
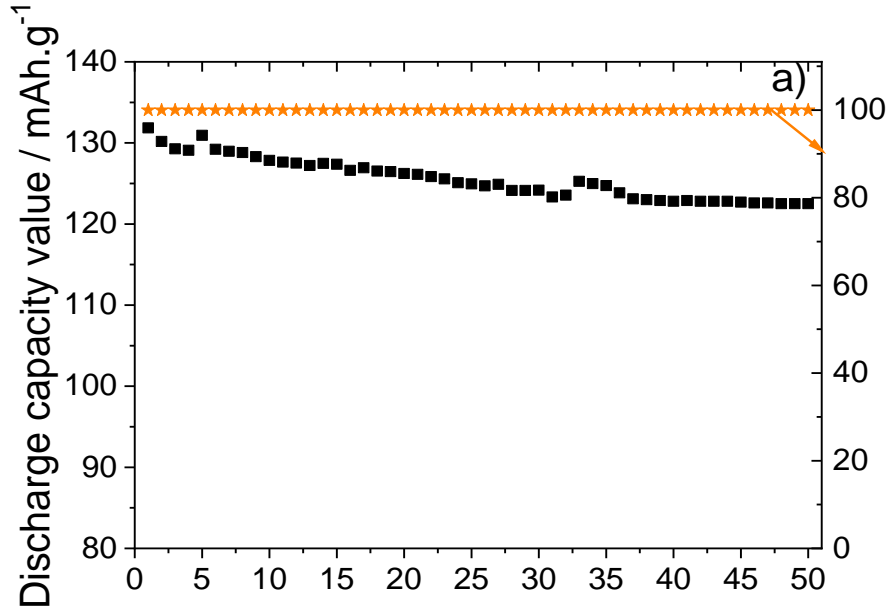

Cycle number

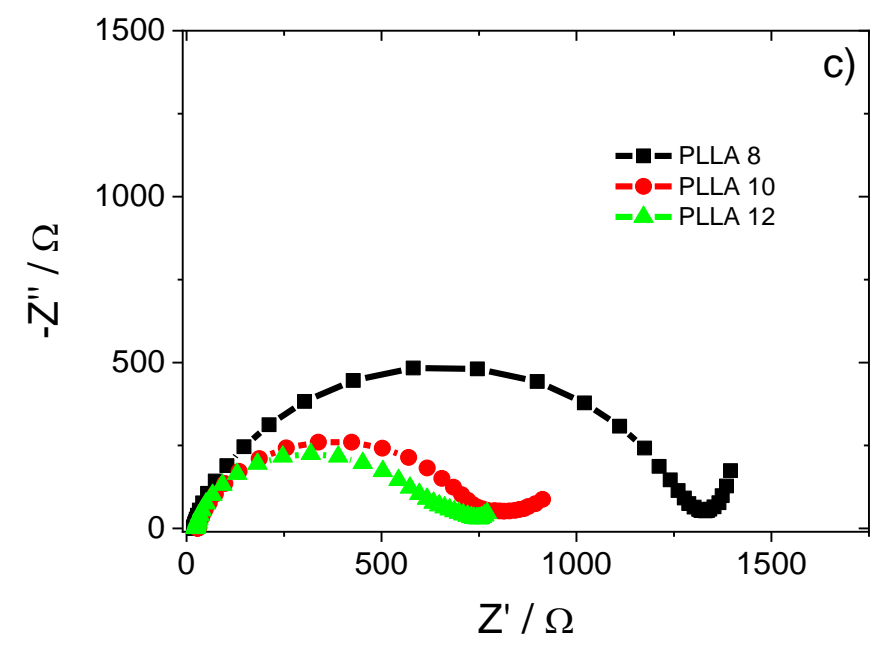

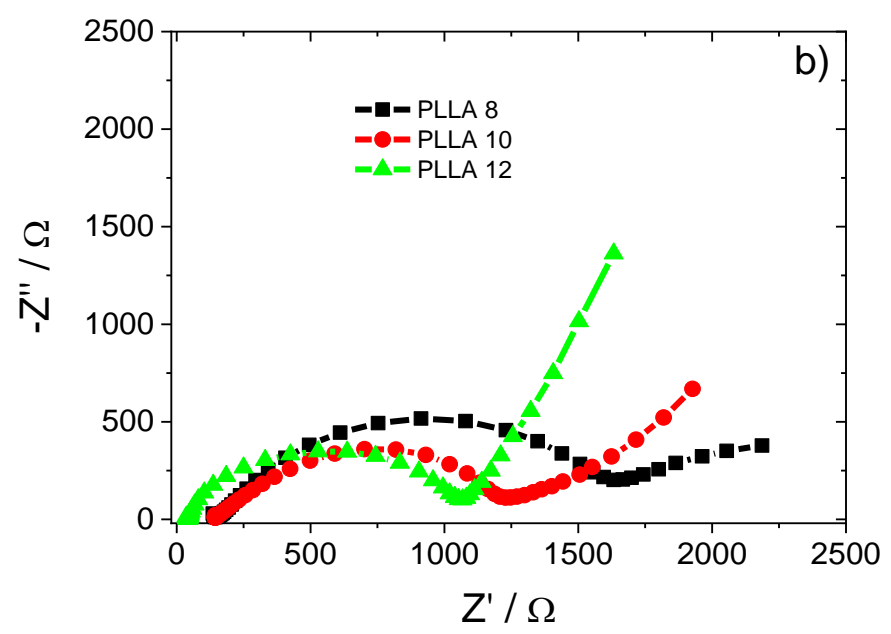

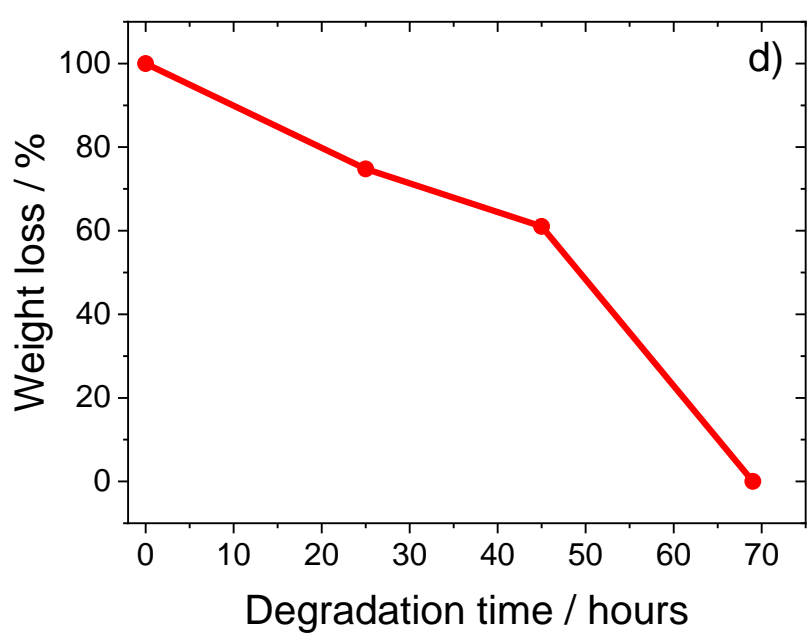

Figure 5 - a) Discharge capacity value and coulombic efficiency at C/5 rate for half-cells with PLLA 10 separator membranes. Electrochemical impedance spectroscopy b) before and c) after cycling of the batteries with all PLLA membranes and d) weight loss as a function of the degradation time for PLLA 10 in a $\mathrm{NaOH}$ solution. 
Before cycling (Figure 5b)), the overall resistance values are 1668, 1235 and $1062 \Omega$ for PLLA 8, PLLA 10 and PLLA 12, respectively, indicating that the resistance value is due to the solid electrolyte interface (SEI) layer formation. After cycling (Figure 5c)), the overall resistances values are 1333, 823 and $743 \Omega$ for PLLA 8, PLLA 10 and PLLA 12, respectively, showing the formation of a very stable SEI layer for all PLLA membranes, which facilitates lithium ion transport.

Considering the environmental issues and in order to evaluate the reuse of PLLA membranes, their degradability was confirmed by the evaluation of the weight loss as a function of time in a $\mathrm{NaOH}$ solution (Figure $5 \mathrm{~d}$ )). The degradation process took place by immersing the membranes in a $0.1 \mathrm{M} \mathrm{NaOH}$ solution with $\mathrm{pH} 13$ at room temperature. Only the weight loss curve for PLLA 10 is shown, being representative of the rest. Regardless of the PLLA membrane, Figure 5d) shows that after 70 hours, the membranes are completely degraded.

Considering that it is essential to obtain sustainable materials for lithium-ion batteries, in order to reduce the environmental impact and contribute to the circular economy paradigm, Table 3 shows the comparison of the PLLA membrane with other natural polymers already used in this field and with commercial separator (Celgard® 2400), attending their porosity, uptake, ionic conductivity and discharge capacity.

Table 3 - Left: Porosity and electrolyte uptake value of separator membranes based on natural polymers, as well as for a commercial separator. Right: comparison of the ionic conductivity and discharge capacity of the same separators with $\mathrm{LiPF}_{6}$ as electrolyte. 


\begin{tabular}{|c|c|c|}
\hline $\begin{array}{c}\text { Natural } \\
\text { polymer }\end{array}$ & $\begin{array}{c}\text { Porosity/ } \\
\text { Uptake } \\
(\%)\end{array}$ & Ref \\
\hline $\begin{array}{c}\text { Cladophora } \\
\text { Cellulose }\end{array}$ & $46 /---$ & {$[66]$} \\
\hline $\begin{array}{c}\text { Cellulose + } \\
\text { titania particles }\end{array}$ & $79 /---$ & {$[24]$} \\
\hline PVA & $62 / 230$ & {$[25]$} \\
\hline Silk fibroin & $90 / 350$ & {$[67]$} \\
\hline PLLA & $72 / 345$ & $\begin{array}{c}\text { In this } \\
\text { work }\end{array}$ \\
\hline $\begin{array}{c}\text { Commercial } \\
\text { separator }\end{array}$ & $\begin{array}{c}\text { Porosity/ } \\
\text { Uptake } \\
(\%)\end{array}$ & Ref \\
\hline Celgard® 2400 & $32 /---$ & {$[56]$} \\
\hline
\end{tabular}

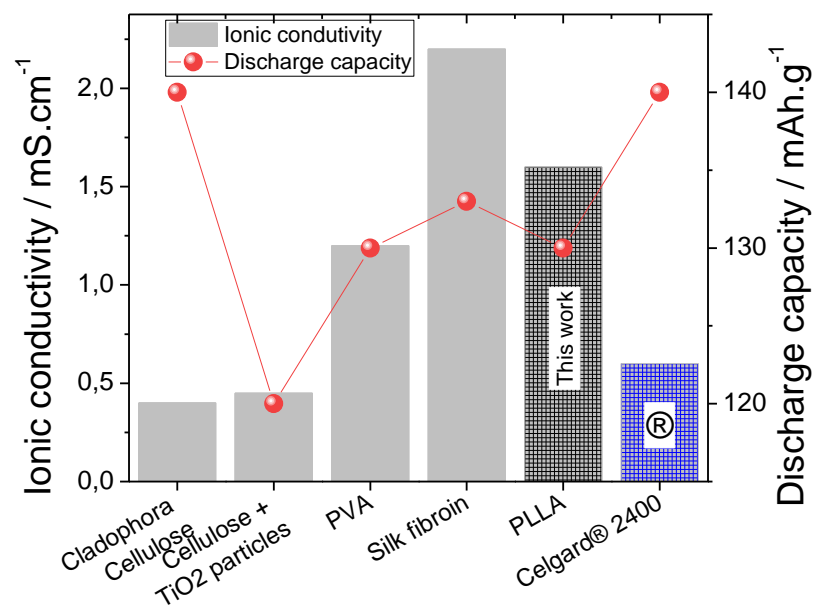

Analyzing Table 3, it is observed that the battery performance of PLLA membranes is similar and, in certain cases, higher when compared to other natural polymers (Table 3 , right). Just like other natural polymers, PLLA separators have significantly higher porosity and better ionic conductivity than conventional separators. Considering the high reusability potential for the PLLA polymer, its application in LIBs offers a different approach to the field of environmental friendlier and degradable batteries. Its similar performance when compared to other natural polymers, associated with the wellestablished and simple processing and recycling processes, makes PLLA a good candidate for the production of greener and more environmentally friendly batteries.

Thus, the present work demonstrates that PLLA is a suitable polymer for battery applications, allowing to tailor its morphology for the development of high-performance separator membranes and representing an advance in the development of environmental friendlier energy storage systems. 


\section{Conclusions}

Lithium-ion battery separator membranes based on poly (L-lactic acid) (PLLA) are presented in order to address the environmental impact of the polymers used in energy storage systems.

PLLA separators were developed varying the polymer concentration between $8 \mathrm{wt} . \%$ to $12 \mathrm{wt} \%$ in a mixture of DMC/DMF solvent and produced by solvent casting technique with thermal induced phase separation.

It is shown that the polymer concentration affects the microstructure and morphology of the membranes, being observed the presence of macro-voids as the polymer concentration increase. No chemical changes are observed before and after the electrolyte uptake. Additionally, the polymer concentration does not significantly change the thermal properties and dimensionality of the membrane. It was also demonstrated a correlation between surface area and ionic conductivity values for these membranes. The highest conductivity vale was observed for the PLLA membrane with $10 \mathrm{wt} . \%$ of polymer concentration in solution. For this membrane, the ionic conductivity value, tortuosity and MacMullin number are $1.6 \mathrm{mS} . \mathrm{cm}^{-1}, 2.3$ and 7, respectively.

With respect to battery performance, the discharge capacity values at $1 \mathrm{C}$-rate are 93,82 and $23 \mathrm{mAh} \cdot \mathrm{g}^{-1}$ for PLLA 10, PLLA 12 and PLLA 8, respectively, a value which is related to the ionic conductivity value. This PLLA separator shows similar performance when compared to other separators produced from natural polymers as well as when compared to commercial separators, demonstrating its suitability for battery applications.

Thus, it is concluded that PLLA is a suitable material for battery separators, leading to high battery performance and representing a suitable candidate for the transition to the use of sustainable materials and to improve the circular economy paradigm within the energy storage field. 


\section{Acknowledgements}

Work supported by the Portuguese Foundation for Science and Technology (FCT) undes strategic funding UID/FIS/04650/2020 and UID/QUI/0686/2020, project PTDC/FISMAC/28157/2017, and Grants SFRH/BD/140842/2018 $\quad$ (J.C.B.), SFRH/BPD/121526/2016 (D.M.C), CEECIND/00833/2017 (R.G.) and SFRH/BPD/112547/2015 (C.M.C.). Financial support from the Basque Government Industry Department under the ELKARTEK and HAZITEK programs is also acknowledged. Technical and human support provided by SGIker (UPV/EHU, MICINN, GV/EJ, EGEF and ESF) is gratefully acknowledged.

\section{References}

[1] A.M. Stephan, S. Thomas, ELECTROLYTES | Gel, in: G. Editor-in-Chief: Jürgen (Ed.) Encyclopedia of Electrochemical Power Sources, Elsevier, Amsterdam, 2009, pp. 140-152.

[2] P. Harrop, H. Zervos, Batteries, Supercapacitors, Alternative Storage for Portable Devices 2009-2019, in, IDTechEx, 2010.

[3] H.S. Choi;, C.R. Park, Lithium-ion Batteries, in: C.R. Park (Ed.), Intech, 2010.

[4] P.B. Balbuena, Y. Wang, Lithium-Ion Batteries: Solid-Electrolyte Interphase, Imperial College Press, 2004.

[5] B. Scrosati, J. Garche, Journal of Power Sources, Lithium batteries: Status, prospects and future, 195 (2010) 2419-2430.

[6] M. Yoshio, R.J. Brodd, A. Kozawa, Lithium-Ion Batteries: Science and Technologies, Springer New York, 2010.

[7] C.M. Costa, E. Lizundia, S. Lanceros-Méndez, Progress in Energy and Combustion Science, Polymers for advanced lithium-ion batteries: State of the art and future needs on polymers for the different battery components, 79 (2020) 100846.

[8] C.M. Costa, Y.-H. Lee, J.-H. Kim, S.-Y. Lee, S. Lanceros-Méndez, Energy Storage Materials, Recent advances on separator membranes for lithium-ion battery applications: From porous membranes to solid electrolytes, 22 (2019) 346-375. 
[9] K.M. Abraham, M. Alamgir, D.K. Hoffman, Journal of The Electrochemical Society, Polymer Electrolytes Reinforced by Celgard® Membranes, 142 (1995) 683-687.

[10] P. Arora, Z. Zhang, Chemical Reviews, Battery Separators, 104 (2004) 4419-4462.

[11] C.M. Costa, L.C. Rodrigues, V. Sencadas, M.M. Silva, S. Lanceros-Méndez, Solid State Ionics, Effect of the microsctructure and lithium-ion content in poly[(vinylidene fluoride)-co-trifluoroethylene]/lithium perchlorate trihydrate composite membranes for battery applications, 217 (2012) 19-26.

[12] Seeram Ramakrishna, Kazutoshi Fujihara, Teik-Cheng Lim, Wee-Eong Teo, Z. Ma, An Introduction To Electrospinning And Nanofibers, World Scientific, New York, 2005. [13] D.-W. Kim, J.-M. Ko, J.-H. Chun, S.-H. Kim, J.-K. Park, Electrochemistry Communications, Electrochemical performances of lithium-ion cells prepared with polyethylene oxide-coated separators, 3 (2001) 535-538.

[14] X. Yu, J. Joseph, A. Manthiram, Materials Horizons, Suppression of the polysulfideshuttle behavior in $\mathrm{Li}-\mathrm{S}$ batteries through the development of a facile functional group on the polypropylene separator, 3 (2016) 314-319.

[15] J.-H. Cho, J.-H. Park, J.H. Kim, S.-Y. Lee, Journal of Materials Chemistry, Facile fabrication of nanoporous composite separator membranes for lithium-ion batteries: poly(methyl methacrylate) colloidal particles-embedded nonwoven poly(ethylene terephthalate), 21 (2011) 8192-8198.

[16] D. Li, D. Shi, K. Feng, X. Li, H. Zhang, Journal of Membrane Science, Poly (ether ether ketone) (PEEK) porous membranes with super high thermal stability and high rate capability for lithium-ion batteries, 530 (2017) 125-131.

[17] T.H. Cho, T. Sakai, S. Tanase, K. Kimura, Y. Kondo, T. Tarao, M. Tanaka, Electrochemical and Solid-State Letters, Electrochemical Performances of Polyacrylonitrile Nanofiber-Based Nonwoven Separator for Lithium-Ion Battery, 10 (2007) A159.

[18] J. Shayapat, O.H. Chung, J.S. Park, Electrochimica Acta, Electrospun polyimidecomposite separator for lithium-ion batteries, 170 (2015) 110-121.

[19] M. Yanilmaz, J. Zhu, Y. Lu, Y. Ge, X. Zhang, Journal of Materials Science, Highstrength, thermally stable nylon 6,6 composite nanofiber separators for lithium-ion batteries, 52 (2017) 5232-5241.

[20] C.M. Costa, J.L. Gomez Ribelles, S. Lanceros-Méndez, G.B. Appetecchi, B. Scrosati, Journal of Power Sources, Poly(vinylidene fluoride)-based, co-polymer separator electrolyte membranes for lithium-ion battery systems, 245 (2014) 779-786. 
[21] R.E. Sousa, J. Nunes-Pereira, C.M. Costa, M.M. Silva, S. Lanceros-Méndez, J. Hassoun, B. Scrosati, G.B. Appetecchi, Journal of Power Sources, Influence of the porosity degree of poly(vinylidene fluoride-co-hexafluoropropylene) separators in the performance of Li-ion batteries, 263 (2014) 29-36.

[22] I. Kuribayashi, Journal of Power Sources, Characterization of composite cellulosic separators for rechargeable lithium-ion batteries, 63 (1996) 87-91.

[23] V.H. Nguyen, D.-H. Lee, S.-Y. Baek, Y.H. Kim, Materials Letters, Recycling different eggshell membranes for lithium-ion battery, 228 (2018) 504-508.

[24] D. Boriboon, T. Vongsetskul, P. Limthongkul, W. Kobsiriphat, P. Tammawat, Carbohydrate Polymers, Cellulose ultrafine fibers embedded with titania particles as a high performance and eco-friendly separator for lithium-ion batteries, 189 (2018) 145151.

[25] W. Xiao, L. Zhao, Y. Gong, J. Liu, C. Yan, Journal of Membrane Science, Preparation and performance of poly(vinyl alcohol) porous separator for lithium-ion batteries, 487 (2015) 221-228.

[26] H. Tsuji, H. Daimon, K. Fujie, Biomacromolecules, A New Strategy for Recycling and Preparation of Poly(l-lactic acid): Hydrolysis in the Melt, 4 (2003) 835-840.

[27] L. Pellegrino, R. Cocchiola, I. Francolini, M. Lopreiato, A. Piozzi, R. Zanoni, A. Scotto d'Abusco, A. Martinelli, Colloids and Surfaces B: Biointerfaces, Taurine grafting and collagen adsorption on PLLA films improve human primary chondrocyte adhesion and growth, 158 (2017) 643-649.

[28] Y. Koide, H. Ikake, Y. Muroga, S. Shimizu, Polymer Journal, Effect of the castsolvent on the morphology of cast films formed with a mixture of stereoisomeric poly(lactic acids), 45 (2013) 645-650.

[29] J.M. Corey, C.C. Gertz, B.-S. Wang, L.K. Birrell, S.L. Johnson, D.C. Martin, E.L. Feldman, Acta Biomaterialia, The design of electrospun PLLA nanofiber scaffolds compatible with serum-free growth of primary motor and sensory neurons, 4 (2008) 863875.

[30] C. Ribeiro, V. Sencadas, C.M. Costa, J.L. Gómez Ribelles, S. Lanceros-Méndez, Science and Technology of Advanced Materials, Tailoring the morphology and crystallinity of poly(L-lactide acid) electrospun membranes, 12 (2011) 015001.

[31] S. Selvam, W.V. Chang, T. Nakamura, D.M. Samant, P.B. Thomas, M.D. Trousdale, A.K. Mircheff, J.E. Schechter, S.C. Yiu, Tissue Eng Part C Methods, Microporous 
poly(L-lactic acid) membranes fabricated by polyethylene glycol solvent-cast/particulate leaching technique, 15 (2009) 463-474.

[32] M. Yoshida, T. Onogi, K. Onishi, T. Inagaki, Y. Tajitsu, Japanese Journal of Applied Physics, High piezoelectric performance of poly (lactic acid) film manufactured by solidstate extrusion, 53 (2014) 09PC02.

[33] P. Ladpli, R. Nardari, F. Kopsaftopoulos, F.-K. Chang, Journal of Power Sources, Multifunctional energy storage composite structures with embedded lithium-ion batteries, 414 (2019) 517-529.

[34] M. Shah Mohammadi, M.N. Bureau, S.N. Nazhat, 11 - Polylactic acid (PLA) biomedical foams for tissue engineering, in: P.A. Netti (Ed.) Biomedical Foams for Tissue Engineering Applications, Woodhead Publishing, 2014, pp. 313-334.

[35] R.E. Conn, J.J. Kolstad, J.F. Borzelleca, D.S. Dixler, L.J. Filer, B.N. Ladu, M.W. Pariza, Food and Chemical Toxicology, Safety assessment of polylactide (PLA) for use as a food-contact polymer, 33 (1995) 273-283.

[36] T. Radusin, A. Miletic, I. Ristić, B. Pilić, Possibilities of PLA as food packaging material- nano-reinforcement and electrospinning as future perspective, 2016.

[37] M. Ando, H. Kawamura, K. Kageyama, Y. Tajitsu, Japanese Journal of Applied Physics, Film Sensor Device Fabricated by a Piezoelectric Poly(L-lactic acid) Film, 51 (2012).

[38] M. Malinconico, E.T.H. Vink, A. Cain, Applications of Poly(lactic Acid) in Commodities and Specialties, in: M.L. Di Lorenzo, R. Androsch (Eds.) Industrial Applications of Poly(lactic acid), Springer International Publishing, Cham, 2018, pp. 3550 .

[39] R. Auras, B. Harte, S. Selke, Macromolecular Bioscience, An Overview of Polylactides as Packaging Materials, 4 (2004) 835-864.

[40] D. Maga, M. Hiebel, N. Thonemann, Resources, Conservation and Recycling, Life cycle assessment of recycling options for polylactic acid, 149 (2019) 86-96.

[41] M. Zhu, J. Lan, C. Tan, G. Sui, X. Yang, Journal of Materials Chemistry A, Degradable cellulose acetate/poly-1-lactic acid/halloysite nanotube composite nanofiber membranes with outstanding performance for gel polymer electrolytes, 4 (2016) 1213612143.

[42] L. Li, M. Yu, F. Wang, X. Zhang, Z. Shao, Energy Technology, Synergistically Suppressing Lithium Dendrite Growth by Coating Poly-l-Lactic Acid on Sustainable Gel Polymer Electrolyte, 7 (2019) 1800768. 
[43] Y.L. Thuyavan, N. Anantharaman, G. Arthanareeswaran, A.F. Ismail, Journal of Chemical Technology \& Biotechnology, Impact of solvents and process conditions on the formation of polyethersulfone membranes and its fouling behavior in lake water filtration, 91 (2016) 2568-2581.

[44] N. Ismail, N. Jakariah, N. Bolong, S. Anissuzaman, N.A.H. Md. Nordin, A. Razali, Journal of Applied Membrane Science \& Technology, Effect of Polymer Concentration on the Morphology and Mechanical Properties of Asymmetric Polysulfone (PSf) Membrane, 21 (2017).

[45] B. Jiang, B. Wang, L. Zhang, Y. Sun, X. Xiao, N. Yang, H. Dou, Separation Science and Technology, Preparation of poly(L-lactic acid) membrane from solvent mixture via immersion precipitation, 51 (2016) 2940-2947.

[46] E. Al Tawil, A. Monnier, Q.T. Nguyen, B. Deschrevel, European Polymer Journal, Microarchitecture of poly(lactic acid) membranes with an interconnected network of macropores and micropores influences cell behavior, 105 (2018) 370-388.

[47] G.R. Guillen, Y. Pan, M. Li, E.M.V. Hoek, Industrial \& Engineering Chemistry Research, Preparation and Characterization of Membranes Formed by Nonsolvent Induced Phase Separation: A Review, 50 (2011) 3798-3817.

[48] L.D. Kock, M.D.S. Lekgoathi, P.L. Crouse, B.M. Vilakazi, Journal of Molecular Structure, Solid state vibrational spectroscopy of anhydrous lithium hexafluorophosphate (LiPF6), 1026 (2012) 145-149.

[49] V. Sencadas, C.M. Costa, G. Botelho, C. Caparrós, C. Ribeiro, J.L. Gómez-Ribelles, S. Lanceros-Mendez, Journal of Macromolecular Science, Part B, Thermal Properties of Electrospun Poly(Lactic Acid) Membranes, 51 (2012) 411-424.

[50] T. Ould Ely, D. Kamzabek, D. Chakraborty, Frontiers in Energy Research, Batteries Safety: Recent Progress and Current Challenges, 7 (2019).

[51] I.A. Neumann, T.H.S. Flores-Sahagun, A.M. Ribeiro, Polymer Testing, Biodegradable poly (1-lactic acid) (PLLA) and PLLA-3-arm blend membranes: The use of PLLA-3-arm as a plasticizer, 60 (2017) 84-93.

[52] E. Shekarian, M.R. Jafari Nasr, T. Mohammadi, O. Bakhtiari, M. Javanbakht, Journal of Nanostructures, Enhanced wettability and electrolyte uptake of coated commercial polypropylene separators with inorganic nanopowders for application in lithium-ion battery, 9 (2019) 736-750. 
[53] H. Liu, Z. Dai, J. Xu, B. Guo, X. He, Journal of Energy Chemistry, Effect of silica nanoparticles/poly(vinylidene fluoride-hexafluoropropylene) coated layers on the performance of polypropylene separator for lithium-ion batteries, 23 (2014) 582-586.

[54] M. Yanilmaz, C. Chen, X. Zhang, Journal of Polymer Science Part B: Polymer Physics, Fabrication and characterization of SiO2/PVDF composite nanofiber-coated PP nonwoven separators for lithium-ion batteries, 51 (2013) 1719-1726.

[55] J. Hassoun, D.-J. Lee, Y.-K. Sun, B. Scrosati, Solid State Ionics, A lithium ion battery using nanostructured $\mathrm{Sn}-\mathrm{C}$ anode, $\mathrm{LiFePO} 4$ cathode and polyethylene oxidebased electrolyte, 202 (2011) 36-39.

[56] D. Djian, F. Alloin, S. Martinet, H. Lignier, J.Y. Sanchez, Journal of Power Sources, Lithium-ion batteries with high charge rate capacity: Influence of the porous separator, 172 (2007) 416-421.

[57] J. Landesfeind, J. Hattendorff, A. Ehrl, W.A. Wall, H.A. Gasteiger, Journal of The Electrochemical Society, Tortuosity Determination of Battery Electrodes and Separators by Impedance Spectroscopy, 163 (2016) A1373-A1387.

[58] J. Weidner, Separators and Membranes for Batteries, Capacitors, Fuel Cells, and Other Electrochemical Systems, Electrochemical Society, 2009.

[59] C. Fongy, A.C. Gaillot, S. Jouanneau, D. Guyomard, B. Lestriez, Journal of The Electrochemical Society, Ionic vs Electronic Power Limitations and Analysis of the Fraction of Wired Grains in LiFePO[sub 4] Composite Electrodes, 157 (2010) A885.

[60] B.E. Logan, E. Zikmund, W. Yang, R. Rossi, K.-Y. Kim, P.E. Saikaly, F. Zhang, Environmental Science \& Technology, Impact of Ohmic Resistance on Measured Electrode Potentials and Maximum Power Production in Microbial Fuel Cells, 52 (2018) 8977-8985.

[61] A. Gören, D. Cíntora-Juárez, P. Martins, S. Ferdov, M.M. Silva, J.L. Tirado, C.M. Costa, S. Lanceros-Méndez, Energy Technology, Influence of Solvent Evaporation Rate in the Preparation of Carbon-Coated Lithium Iron Phosphate Cathode Films on Battery Performance, 4 (2016) 573-582.

[62] J. Cao, Y. Qu, R. Guo, Electrochimica Acta, La0.6Sr0.4CoO3- $\delta$ modified LiFePO4/C composite cathodes with improved electrochemical performances, 67 (2012) 152-158.

[63] A. Eftekhari, Sustainable Energy \& Fuels, Energy efficiency: a critically important but neglected factor in battery research, 1 (2017) 2053-2060. 
[64] J. Guo, A. Sun, X. Chen, C. Wang, A. Manivannan, Electrochimica Acta, Cyclability study of silicon-carbon composite anodes for lithium-ion batteries using electrochemical impedance spectroscopy, 56 (2011) 3981-3987.

[65] G.A. Williamson, V.W. Hu, T.B. Yoo, M. Affandy, C. Opie, E.K. Paradis, V.C. Holmberg, ACS Applied Energy Materials, Temperature-Dependent Electrochemical Characteristics of Antimony Nanocrystal Alloying Electrodes for Na-Ion Batteries, 2 (2019) 6741-6750.

[66] R. Pan, O. Cheung, Z. Wang, P. Tammela, J. Huo, J. Lindh, K. Edström, M. Strømme, L. Nyholm, Journal of Power Sources, Mesoporous Cladophora cellulose separators for lithium-ion batteries, 321 (2016) 185-192.

[67] A. Reizabal, R. Gonçalves, A. Fidalgo-Marijuan, C.M. Costa, L. Pérez, J.-L. Vilas, S. Lanceros-Mendez, Journal of Membrane Science, Tailoring silk fibroin separator membranes pore size for improving performance of lithium ion batteries, 598 (2020) 117678. 